\title{
LETTERS
}

\section{One EHR should not rule them all}

There is much hope in being able to leverage technology to improve health care, and understandably much frustration when it does not deliver as quickly as hoped. However, as with any cycle, it is important to avoid the lows as well as the highs. We should not lose sight of the goal and not forget to understand the underlying issues.

In an editorial published in CMAJ, Dr. Nav Persaud's assertion that interoperability is an "unsolvable problem" that could be solved with a single company health record is not borne out with fact in the Canadian system. ${ }^{1}$ Health information exchange systems like those in Ontario (ClinicalConnect, ConnectingGTA) are proof that records can, and are, being accepted and transferred between different sites. The Ontario Laboratories Information System stores and transmits information to a multitude of inpatient and outpatient electronic health records. The challenge is not to provide a single technological platform, but to break down the barriers to interoperability that are created when business models are threatened and privacy laws are outdated.

Our local experience in the implementation of a commercial enterprise-wide electronic health record (EHR) has taught us that customization of a local instance of software leads to forks in that software that make interoperability with other instances difficult and does not solve the interoperability problem. This is not unique to our hospital; given the countless differences in everything from nomenclature to business logic between medical organizations, there is simply no benefit in trying to employ "one-size-fits-all" solutions. In health care, forcing all practitioners to conform to a single product serves only to guarantee the inefficiency of this product.

The idea that open-source software could be the solution also ignores the real challenge of maintaining and developing a highly complex piece of software for all stakeholders in the health care system. Major university health systems in the United States have moved away from customizable software to commercial instances because of these challenges. ${ }^{2}$ The current landscape of providers stuck with a poor EHR would be magnified when all development is given to a monopoly.

Even if all health care providers did use the same EHR product, their data would not suddenly become interoperable. In fact, interoperability of health care data has existed for decades with Health Level Seven International (HL7). This is why health information exchange is effective - each provider is able to use technology in the way that is most beneficial to their practice, and is responsible only for outputting the requested data in a standardized fashion. This approach is accepted in other professions: for example, shareholder documents (balance sheet, income statement) follow a standard format, but internally each company is able to track its expenses in a way that best suits its specific business.

The problem is not each individual EHR platform; the problem is the lack of incentive for alignment and a paucity of regulation to enable interoperability. Standards already exist for semantic transfer of information. What we need is not another large public failure of implementation of information technology, ${ }^{3}$ but a bold push toward regulated interoperability requirements and modernization of privacy laws.

\section{Steven C. Wong MD MHI}

Assistant professor; physician informatician, General Internal Medicine, McMaster University, Hamilton, Ont.

\section{Charles Osborne MHI}

Project manager ICAT Redevelopment, West Park Healthcare, University of

Toronto, Toronto, Ont.

Cite as: CMAJ 2019 July 29;191:E844. doi: $10.1503 / \mathrm{cmaj} .72273$

\section{References}

1. Persaud N. A national electronic health record for primary care. CMAJ 2019;191:E28-9.

2. McCluskey PD. Partners' $\$ 1.2 \mathrm{~b}$ patient data system seen as key to future. Boston Globe 2018 June 1. Available: www.bostonglobe.com/ business/2015/05/31/partners-launches-billion -electronic-health-records-system/oo4nJJW2rQyf WUWQlvydkK/story.html (accessed 2019 Feb. 11).

3. The electronic health records system in the UK. Centre for Public Impact; 2017. Available: www. centreforpublicimpact.org/case-study/electronic -health-records-system-uk/ (accessed 2019 Feb. 11).

Competing interests: None declared. 